\title{
Membangun Generasi Berkualitas dari Keluarga melalui Pencegahan dari Pelecehan Seksual Anak Sejak Dini
}

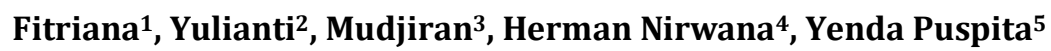

1,5Sekolah Tinggi Ilmu Tarbiyah Al-Kifayah Riau

2Sekolah Tinggi Agama Islam Maarif Jambi

3,4Universitas Negeri Padang

E-mail: fitriana1410@gmail.com

Article Info
Article History
Received: 2021-11
Revised: 2021-11-28
Published: 2021-12-0

Keywords:
Family;
Quality Generation;
Sexual harassment;
Child

Child.

\begin{abstract}
In today's global era, technology cannot be separated from human life. Through technology, it is easier for generations to self-actualize so that they can develop optimally into quality generations, but on the other hand it is also a challenge, especially for generations, one of which is pornography. Children as the generation that is expected to become the golden Indonesia in 2045 as an asset in the implementation, so that preventive efforts from sexual harassment are needed, so that efforts are needed to implement families in forming a quality generation to prevent sexual harassment from an early age, using the library research method. The method of data collection is documentation. Next with data analysis techniques. This article aims to review the implementation of families in forming a quality generation that is prevented from sexual harassment from an early age. The implementation of families in forming a quality generation is family education that is attentive, exemplary, paying attention to bihifzi anwalihim (guarding their property, food from halal), bihusni tarbiyatihim (forming good education) and wa taf adza adhum (rejecting disease from them, children are physically and psychologically healthy). In addition, in terms of physical, psychological, spiritual, and social and cultural aspects, parenting, reproductive knowledge, getting sex education, character values, religion, controlling children from daily life, spectacle, communication patterns, openness, intimacy, healthy interactions, and other.
\end{abstract}

\begin{tabular}{l}
\hline Artikel Info \\
\hline Sejarah Artikel \\
Diterima: $2021-11-10$ \\
Direvisi: 2021-11-28 \\
Dipublikasi: 2021-12-06
\end{tabular}

Kata kunci:

Keluarga;

Generasi Berkualitas;

Pelecehan Seksual;

Anak.

\begin{abstract}
Abstrak
Di era global saat ini, teknologi tidak lepas dari kehidupan manusia. Melalui teknologi mempermudah generasi dalam mengakutalisasikan diri sehingga mampu berkembang secara optimal menjadi generasi berkualitas, namun di sisi lain juga menjadi tantangan terutama bagi generasi, salah satunya pornografi. Anak sebagai generasi yang diharapkan menjadi Indonesia emas tahun 2045 sebagai aset dalam implementasi tersebut, sehingga diperlukan upaya preventif dari pelecehan seksual tersebut, sehingga diperlukan upaya implementasi keluarga dalam membentuk generasi berkualitas tercegah dari pelecehan seksual sejak dini, dengan menggunakan metode studi kepustakaan (library reseach), Metode pengumpulan data yakni dokumentasi. Selanjutnya dengan teknik analisis data. Artikel ini bertujuan mengulas terkait implementasi keluarga dalam membentuk generasi berkualitas tercegah dari pelecehan seksual sejak dini, Adapun implementasi keluarga dalam membentuk generasi berkualitas yakni pendidikan keluarga yang penuh perhatian, teladan, memperhatikan bihifzi anwalihim (menjaga harta, makanan mereka dari yang halal), bihusni tarbiyatihim (membentuk pendidikan yang baik) dan wa taf adza adhum (menolak penyakit dari mereka, anak sehatsexcara fisik dan psikis). Selain itu, dari segi fisik, psikis, spiritual, dan sosial dan budaya kulturla, pola asuh, pengetahuan reproduksi, mendapat sex education, nilai karakter, agama, mengontrol anak dari keseharian, tontonan, pola akomunikasi, keterbukaan, keakraban, interaksi sehat, dan lainnya.
\end{abstract}

\section{PENDAHULUAN}

Di era revolusi 4.0 saat ini, kehidupan manusia tidak terlepas dengan teknologi, mulai dari seseorang bekerja di rumah, bekerja, belajar, hiburan, tidak terlepas dengan teknologi. Melalui perkembangan tersebut, segala kemudahan didapatkan dalam segala aspek, seperti mudah lancar berkomunikasi dan mendapatkan informasi. Namun selain sebagai peluang, kenyataan ini juga menjadi tantangan, misalnya 
informasi yang di dapatkan tidak semua mengenai hal positif dan sesuai dengan tahap perkembangan seseorang, misalnya anakanak/remaja melihat berita/gambar pornografi. Penggunaan teknologi seperti laptop, computer, handphone android sebagai sumber segala informasi, baik berupa berita, gambar, video, dan lainnya bisa didapat/ dilihat oleh siapa saja, mulai dari tingkat dini, anak, remaja sampai tingkat dewasa. Kondisi ini jika terus berlanjut maka dimulai dari melihat, penasaran, dan satisfaction ke depan bisa berlanjut pada keinginan mencoba dengan tanpa tanggungjawab dan kognitif yang matang. Selanjutnya, agar pelampiasan tersebut bisa dilakukan dengan tanpa resiko yang berbahaya, maka sebagai objek, mengarah pada anak yang notabane sebagian besar sosok yang minim informasi, bisa diiming-iming dengan makanan atau mainan, selain itu mayoritas anak-anak lemah dalam hal fisik, ia tidak berani melawan apalagi ditambah dengan ancaman tertentu.

Anak yang mengalami objek tersebut dikatakan sebagai korban pelecehan seksual. Biasanya anak belum begitu bisa berkomunikasi dengan orangtua atau orang terdekat, walau sebenarnya komunikasi ini penting dilakukan, karena keterampilan berkomunikasi anak yang minim, ketakutan, malu atau bahkan belum mengetahui berbuat apa, sehingga hal ini membuat kasus pelecehan seksual semakin bertambah tiap tahunnya, apalagi dengan kondisi pandemic saat ini. Handayani dkk. (2017); Justicia (2017) menyatakan bahwa komunikasi begitu diperlukan, terutama orangtua dan anak.

Berdasarkan data tahun 2012 ditemukan 9,3\% kasus penganiayaan anak tergolong pelecehan seksual (National Sex Offender Public Website (NSOPW, 2012) dan kasus pelecehan seksual anak berdasar hasil laporan sebanyak 62,939 kasus di tahun 2012. Selanjutnya di tahun 2013 pihak KPAI menangani 925 kasus pelecehan seksual yang terdiri dari keluarga/kerabat, pendidik, teman sekitar sebagai pelaku. David (2014) bahkan tiga tahun terakhir sekitar 3500-3600 kasus tersebut dibawah naungan KPAI menanganinya. Data lainnya sebanyak 120 juta anak di dunia pernah menjadi korban pelecehan seksual, terutama di usia anak di bawah 20 tahun (UNICEF, 2014). Di Indonesia terdapat kenaikan $100 \%$ dari tahun 2013 menuju 2014, korban hingga pelaku pelecehan seksual sehingga oleh Komisi Perlindungan Anak Indonesia (KPAI) terjadi peningkatan setiap tahunnya Hal ini berdampak pada kondisi tahun 2020 saat ini, Amrullah (2020) mengungkapkan pelecehan seksual pada anak meningkat apalagi dengan kondisi pandemic saat ini ditemukan data sebanyak 8.259 kasus bertambah menjadi 11.797 kasus yang terjadi pada bulan Juli-Agustus 2020.

Berdasarkan data di atas, terlihat bahwa anak sebagai agent perubahan yang keberadaannya menjadi estapet masa depan menuju Indoneisa emas tahun 2045, tentu untuk menjadi generasi berkualitas tersebt, anak penting agar terhindar dari pelecehan seksual baik sebagai korban atau pelaku. Hal ini diperkuat dengan perhatian pemerintah terhadap anak. Di dalam UU nomor 23 tahun 2002 pasal 1 ayat 12 berisi bahwa anak memliki hak dan juga HAM, terdapat jaminan, perlindungan, pemenuhan terhadap mereka dengan berbagai aspek, baik orangtua, keluarga, masyarakat, negara, dan pemerintah. Pada pasal 9 ayat 1 juga dikatakan bahwa anak memiliki hak dalam proses perkembangan kea rah optimal, sesuai dengan bakat dan minat. Pada pendidikan anak dalam jenjang pendidikan diperlukan perlindungan dari pelecehan seksual, dengan berbagai profesi dan hubungan dengan anak, baik keluarga, orang yang dikenal seperti pendidik, teman atau yang tidak dikenal.

Selanjutnya, kesehatan anak baik fisik atau mental perlu dikembangkan secara optimal, dengan tercegah dari pelecehan seksual agar menjadi generasi berkualitas. Untuk dapat diimplementasikan hal ini, perlu adanya implementasi keluarga. Keluarga sebagai lingkungan pertama bagi anak. Pilar inilah yang membentuk baik buruknya anak menuju generasi berkualitas atau sebaliknya. Melalui keluarga, pola pikir, sikap, kepribadian, agama ditanamkan. Implementasi keluarga juga sebagai sumber pengetahuan anak, termasuk tercegah dari pelecehan seksual dan menjadi generasi berkualitas. Berdasarkan ulasan di atas, maka yang menjadi fokus ialah membangun generasi berkualitas dari keluarga melalui pencegahan dari pelecehan seksual anak sejak dini.

\section{METODE PENELITIAN}

Adapun metode yang digunakan ialah library reseach. Studi kepustakaan (library reseach) meliputi mengkaji teori berdasarkan sumber ilmiah/literature ilmiah. Selanjutnya, sumber data diperoleh dari buku, jurnal, atau artikel ilmiah yang sesuai dengan pilihan topic. Riset pustaka (library research), merupakan suatu cara dengan membentuk kerangka penelitian dengan menggunakan media pustaka sebagai cara 
memperoleh data penelitian (Zed, 2014). Data dikumpulkan terintegrasi dengan fokus topic bahasan yakni mengenai implementasi keluarga membentuk generasi berkualitas tercegah dari pelecehan seksual sejak dini.

\section{HASIL DAN PEMBAHASAN}

\section{A. Pelecehan Seksual Anak}

Pelecehan seksual anak ialah suatu tindakan criminal dan sipil, di dalamnya orang dewasa berada pada keterlibatan seksual dengan anak di bawah umur, atau kondisi eksploitasi anak di bawah umur dengan tujuan kepuasan seksual (Masson, 1984). Di dalam Kamus Bahasa Indonesia, kata pelecehan dimulai dari leceh dengan makna penghinaan atau peremehan (Collier, 2000). Selain itu juga dikatakan "harassing". Jika diasosiasikan dengan kata seksual, pelecehan bermakna suatu perilaku atau tindakan bersifat tidak normative yang berhubungan dengan jenis kelamin, tindakan memaksa seseorang berbuat suatu hubungan seksual yang tidak diinginkan juga dikatakan pelecehan seksual. Kegiatan atau perhatian (attention) berkonotasi seksual, bersifat merendahkan, sepihak dan tidak dinginkan oleh korban atau orang yang dikenai objek tersebut yang berdampak pada perasaan malu, marah, tersinggung, pada diri korban pelecehan sosial (Collier, 2002; Utamadi, 2001; Triwijati, 2007; Hastuti, 2014).

Bentuk pelecehan ini menurut Witkowska (2005); dan Chomaria (2014) pelecehan seksual anak dilihat dari segi fisik, verbal dan non verbal, dan visual. Konteks tindakan ini mengarah kepada seksual. Kegiatan seperti pembicaraan seksual, memberikan komentar berbau seksual, menunjukkan alat kelamin pelaku kepada anak, atau body language lainnya, pelecehan seksual ini juga seperti main mata, berkomentar terkait seks, bercanda porno, menepuk atau menyentuh salah satu bagian tubuh, melakukan gerakan/ isyarat seksual, menyolek, mengajak melakukan hubungan seksual, baik bersifat iming-iming atau pemaksaan, isyarat seksual. Pelecehan seksual sebanyak 78\% dilakukan oleh orang dikenal oleh korban, seperti saudara, orangtua tiri, teman dekat, guru atau orang yang tidak dikenal.

Dari ulasan di atas dapat diambil makna bahwa pelecehan seksual merupakan perilaku atau tindakan mengarah pada seseorang berkonotasi dengan seksual, bersifatmerendahkan, memaksa, menurunkan martabat, mengintimidasi baik fisik dan non fisik, verbal, non verbal terkait jenis kelamin yang dilakukan oleh seseorang atau sekelompok orang lawan jenis yang biasanya lebih dominan/ berkuasa, yang tidak disukai, bersifat menganggu, merugikan, tidak diinginkan oleh korban pelecehan seksual.

Beberapa penyebab faktor pelecehan seksual diantaranya 1) pengalaman (experience) bersifat biologis, 2) perisitiwa dari sosial budaya, 3) faktor pendidikan, 4) faktor ekonomi, dan 5) faktor ekonomi (Collier, 2002). Faktor penyebab pelecehan seksual menurut Erlinda (2014) yakni 1) rendahnya pendidikan karakter di rumah oleh keluarga, 2) rendahnya kesadaran masyarakat mengenai hak anak, 3) ekonomi rendah, 4) rendahnya pengetahuan (knowledge) mengenai sex education atau pengetahuan anak mengenai reproduksi 5) penegakan hukum yang lemah, 6) kejahatan yang merajalela.

Implementasi keluarga merupakan hal yang penting, meliputi pola asuh, pola asuh yang bersifat otoriter, atau permisif, seperti memperbolehkan segala hal, atau overporotektif yang berdampak pada pertumbuhan dan perkembangan anak, baik dari aspek pribadi dan sosial, pengetahuan orangtua dan anak mengenai kesehatan reproduksi, perkembangan IT yang terus berkembang, Purnawan (2004) membagi menjadi faktor internal yakni fisik dan psikis, selanjutnya secara eksternal yakni faktor keluarga seperti pola asuh, komunikasi yang kurang, faktor lingkungan, kecanggihan teknologi.

Selanjutnya mengenai kurang pengetahuan ini diperkuat oleh data sekitar $87 \%$ responden yang kurang mempunyai pengetahuan memiliki resiko korban pelecehan seksual. Misalnya anak yang tidak mengetahui mengenai pentingnya menjaga kesehatan reproduksi akan besar berpeluang menjadi korban, begitu sebaliknya. Terkadang kondisi ini terhambat oleh orangtua yang menganggap tabu berbicara mengenai reproduksi begitu juga dengan anak. Romauli (2009); Widyastuti (2009) Kesehatan reproduksi bukan hanya tentang jenis kelamin, namun kondisi fisik, mental, sosial, fungsi dan proses reproduksi, sehingga dikatakan sehat jika terbebas dari penyakit atau cacat terkait reproduksi. 
Pelecehan seksual yang terjadi secara tidak langsung memberikan bekas/ dampak bagi korban, yang tertunya menjadi beban dan hal merugikan. Diantaranya dampak psikis, walau ini juga dipengaruhi tingkat kejadian pelecehan, apakah parah, mengancam, bersifat halus atau kasar, atau bersifat verbal (Collier, 2002).

\section{B. Generasi Berkualitas}

Generasi berkualitas ia yang memiliki intelektual yang baik. Dalam kamus KBBI (2001) yang memiliki intelektual bermakna cerdas, berpikiran jernih sesuai bersifat awareness, menyangkut pemikiran dan pemahaman. Intelektual juga terkait dengan kecerdasan/ intelegensi. Intelegensi bermakna. Kondisi seseorang dalam knowledge, iman, karakter, seni, dalam arti bahwa berkualitas Islami dalam Islam memiliki iman yang hebat, wawasan luas, berkarakter dan terdapat seni yang tinggi (Gullen, 2019). Selain itu terdapat unsur spiritual, mental, dan intelektual, mampu menebarkan kebaikan dengan nilai ukhrawi. Generasi berkualitas Islami dalam Islam ia yang kuat dalam nilai agama dan intelektual demi kebermanfaatan saat ini dan akan datang (Karmiza, 2019). Selanjutnya konsep kualitas menurut Gullen (2019) terdiri dari 1) kualitas iman, 2) Kualitas intelektual/ ilmu pengetahuan, 3) kualitas amal shaleh (akhlak, dan kualitas social, adapun generasi berkualitas tercegah dari pelecehan seksual tidak terjadi dengan begitu saja, namun dipengaruhi oleh beberapa factor, seperti:

\section{1) Keluarga}

Keluarga di dalam pernikahan bertujuan membentuk keluarga bahagia dan sejahtera (Agustian, 2013), dan ini berttik tolak pada anak/ generasi berkualitas. Peranan keluarga sebagai tonggak pertama dalam membentuk generasi berkualitas, yakni dengan melakukan pemeliharaan secara baik. Misalnya dalam hal pertumbuhan dan perkembangan anak. Anak yang berada di lingkungan yang sehat dan harmonis akan tumbuh dengan sehat dan berkembang secara optimal, maka dapat terhindar dari perilaku menyimpang atau dengan pengetahuan dapat menjaga diri dari pelaku pelecehan seksual. Sebagaimana dikatakan bahwa keluarga yang bahagia/ harmonis yang jauh dari ketegangan, kurang komunikasi, rasa kecewa, mampu mengaktualsasikan diri baik fisik, mental, dan sosial (Gunansa, 2000).

2) Lembaga Pendidikan

Lembaga pendidikan merupakan faktor penting dalam membentuk generasi berkualitas tercegah dari pelecehan seksual. Pendidikan khususnya bukan hanya untuk menstranfer ilmu pengetahuan, akan tetapi tata nilai, karakter, norma, dan lainnya. Sebagaimana diungkapkan oleh Fraenkel (1977) bahwa sekolah tidak hanya terkait pengetahuan, namun orientasi pada nilai (valueoriented enterprise). Dalam pencegahan, siswa dapat mengetahui mengenai ilmu reproduksi, pergaulan sehat, dan terhindar dari pergaulan bebas.

3) Lingkungan Masyarakat

Manusia adalah mahkluk sosial, termasuk generasi yang disiapkan menjadi generasi berkualitas tercegah dari pelecehan seksual. Anak merupakan bagian dari masyarakat, pembentukan pola pikir, sikap, karakter juga didapatkan dari masyarakat. Berdasarkan hal ini terungkaplah bahwa lingkungan masyarakat sangat berpengaruh dengan pembentukan kondisi generasi. Situasi masyarakat dengan nilai yang dianutnya, kebiasaan di masyarakat secara tidak langsung mempengaruhi sikap dan pola pikir masyarakat secara masyoritas (Shihab, 1996). Cara pandang yang normative, positif perlu diupayakan dengan kerjasama antar masyarakat, untuk menjadikan generasi berkualitas tercegah dari pelecehan seksual.

4) Negara dan Lingkungan Global

Dalam konteks global saat ini, diharapkan generasi dapat bersiang dan berprestasi secara global. sehingga diperlukan generasi unggul yang mampu secara melakukan kebermanfaatan dari segi reseach, dan pengembangan, yang di dalamnya ada riset-riset unggul (Wibowo, 2017). Dengan demikian, diharapkan negara dan lingkungan global melalui pendidikan juga dapat mencetak generasi berkualitas tercegah dari pelecehan seksual dan unggul secara global. 
C. Implementasi Keluarga dalam Membentuk Generasi Berkualitas Tercegah dari Pelecehan Seksual Anak Sejak Dini

Edukasi mengenai sex education penting agar anak mengetahui peranannya, dan kesehatan reproduksi, seperti perubahan pada fisik, fungsi reproduksi, dan lainnya yang berdampak pada anak siap berada di situasi sosial dengan adaptif, memiliki self confidence yang tinggi dan bertanggungjawab terhadap dirinya (Erlinda, 2014). Sex education seperti pemahaman mengenai kondisi fisik, system dan fungsi reproduksi sehat, interaksi lawan jenis, hingga upaya terhindar dari kejahatan seksual (Jatmikowati, dkk, 2015; Hamun, 2010). Anak yang mendapatkan pola asuh yang tepat akan mengenal mengenai anatomi tubuh, dan lebih selektif dalam menjaga tubuh di situasi sosial. Misalnya Widyastuti (2009) mengungkapkan can dancan't dilihat terkait bagian tubuh di depan orang lain, bahkan dalam dunia medis idealnya atas izin dan dampingan dari orangtua. Jatnikowati (2015); Sugiasih (2011) memperkuat bahwa urgensi sex education diajarkan sejak dini kepada anak d keluarga. Okvitasari (2018) menambahkan bahwa pengajaran tersebut disesuaikan dengan child development.

Impelementasi keluarga agar anak tercegah dari pelecehan seksual juga melalui komunikasi interpersonal yang baik, adanya keterbukaan, kenyamanan dengan anak, begitu sebaliknya, misalnya oleh Alya (2010) di dalam keluarga terdapat pola asuh dengan diskusi, anak diperbolehkan bercerita apapun tentang dirinya atau kejadian yang dialami olehnya di keseharian, terdapat pembatasan jam pembelajaran anak, keluar malam dengan dberi batasan waktu, pengetahuan mengenai wilayah tubuh yang boleh dan tidak boleh secara umum, menseleksi tontonan dan mengontrol kegiatan anak.

Mastra \& Ida (2020) implementasi membangun generasi berkualitas tercegah dari pelecehan seksual dengan memberikan teladan, menciftakan keharmonisan melalui keteladanan, komunikasi. Muslim (2006); Harjana (2009) dengan komunikasi terjalin proses pertukaran makna yang melahirkan pengertian bersama, selanjutnya saling pengertian, memahami kelebihan dan kekurangan, saling bersinergi mengisi kelemahan satu sama lain. Selain itu terciftanya suasana yang akrab seperti ungkapan Didaktika (2018) generasi berkualitas dengan adanya pendidikan karakter yang ditanamkan kepada anak tersebut. Selanjutnya Darma (2017) memperkuat pendidikan karakter merupakan hal yang utama dalam mencetak generasi berkualitas khususnya mempersiapkan generasi emas tahun 2045 di Indonesia, dalam tafsir Muyassar Jilid 1 oleh syekh Al-Allamah oleh Aziz (2012) dijelaskan bahwa terdapat beberapa hal yang diperhatikan keluarga sebagai implementasi dalam membentuk generasi berkualitas yakni Bihifzi anwalihim (Menjaga harta mereka), Bihusni tarbiyatihim (membentuk pendidikan yang baik), Wa taf adza adhum (menolak penyakit dari mereka). Berdasarkan aspek agama, hal ini diperkuat oleh Castro (2006) implementasi keluarga dalam mendidik dari segi agama juga diperlukan dalam membentuk generasi berkualitas, ia yang tercegah maka akan

terus meningkat perkembang anak tersebut. Nilai agama seperti menjaga diri, norma yang diperbolehkan dan sebaliknya, hal ini akan berdampak pada anak tercegah dari pelecehan seksual dan pergaulan besar sebagai tahapan lanjutan ketika sudah remaja nantinya. Implementasi pola asuh orangtua di keluarga sangat berpengaruh dalam menjadikan anak menjadi generasi berkualitas atau sebaliknya, jika dipenuhi dengan remehan, celaan, makian maka anak cenderung negative dan beresiko berperilaku menyimpang (Notle, 1998).

\section{KESIMPULAN}

Keluarga merupakan salah satu pilar pendidikan utama dalam membentuk generasi berkualitas tercegah dari pelecehan seksual sejak dini. Sejak anak dilahirkan hingga anak tumbuh dewasa, oleh karena itu diperlukan upaya persiapan agar agar tumbuh berkembang secara optimal, tercegah dari pelecehan seksual. Pelecehan seksual merupakan tindakan tidak normative, dilakukan oleh pelaku bersifat memaksa, merendahkan, mengintimidasi baik fisik, verbal, non verbal terkait jenis kelamin, membuat marah, tidak disukai, tersinggung, tidak diinginkan korban pelecehan seksual. Impelementasi keluarga terkait hal ini dengan membentuk pendidikan dengan memperhatikan bihifzi anwalihim (menjaga harta, makanan mereka dari yang halal) 
bihusni tarbiyatihim (membentuk pendidikan yang baik) dan wa taf adza adhum (menolak penyakit dari mereka, anak sehat sexcara fisik dan psikis). Selain itu, dari segi fisik, psikis, spiritual, dan sosial dan budaya kultura, pola asuh, pengetahuan reproduksi, nilai karakter, teladan, agama, mengontrol anak dari keseharian, tontonan, pola akomunikasi, keterbukaan, keakraban, interaksi sehat, dan lain,

\section{DAFTAR RUJUKAN}

Alya, A. (2010). Ibu, dari Mana Aku Lahir. Yogyakarta: Pustaka Grahatama.

Aziz. (2012). Ulul Albab Citra Diri dan Religiuitas Mahasiswa di Era Globalisasi. Malang: UIN Maliki Press.

Amrullah, A. (2021). Republika, from https://republika.co.id/berita/i6npr330 /kemensos-kasus-kekerasan-anakmelonjak. diakses Mei 2021.

Bekti Istiyanto, S. (n.d.). Pentingnya Komunikasi Keluarga: Menelaah Posisi Antara Menjadi Wanita Karir Atau Penciptaan Keluarga Berkualitas. No.I, Vol. 2.

Castro, P. B. (2006). Global shadows: Africa In The Neoliberal World Order. Vol. 4, No. 2, 8-10. Chomaria, N. (2014). Pelecehan Anak, Kenali dan Tangani, Menjaga Buah Hati dari Sindrom. Solo: tiga Serangkai.

David, S. (2014). KPAI Kasus Pelecehan Seksual Anak Terjadi di Tahun 2013 dari http://www.kpai.go.id/berita/kpai-925kasus-pelecehan-seksual-anak-terjadi.

Didaktika, Wahana. (2018). Membangun Generasi Berkualitas Islami Melalui Pendidikan Karakter. Vol. 12, No. 1, 42-52.

Erlinda. (2014). Stop Child Abuse: Upaya Peningkatan Perlindungan Anak dari Bahaya Kekerasan, Pelecehan, dan Eksploitasi.

Fraenkel, J. R. (1977). How to Teach about Values: An Analytical Approach, Englewood, NJ: Prentice Hall.

Gunansa. (2000). Psikologi untuk Keluarga. Jakarta: Gunung Mulia.

Hastuti, S. (2014). Pendidikan Seksual Anak di TK dan SD. Yogyakarta: HIMPSI.
Handayani, M., Penelitian, P., Pendidikan, K., \& Kemdikbud, B. (2017). Pencegahan Kasus Kekerasan Seksual pada Anak Melalui Prevention of Sexual Violence Cases In Children Through Interpersonal Communication. Jurnal Ilmiah VISI PGTK PAUD Dan DIKMAS, Vo. 12. No.1.

Hanum, M. (2010). Biologi Reproduksi. Yogyakarta: Nuha Medika. Hurlock, Elisabeth. (1980). Psikologi Perkembangan. Jakarta : Erlangga.

Justicia, R. (2016). Program Underwear Rules untuk Mencegah Kekerasan Seksual pada Anak Usia Dini. Jurnal Pendidikan Usia Dini, Vo. 9, No.2, 217-232.

Jatmikowati. (2015). A model and Material of Sex Education For Early-Aged-Children. Cakrawala Pendidikan, No. 03, 434-448.

Justicia, R. (2017). Pandangan Orang Tua Terkait Pendidikan Seks Untuk Anak Usia Dini.

Early Childhood, Jurnal Pendidikan, Vol.1, No.2, 28-37.

Karmiza, Ebing. (2019). Generasi Penerus Berkualitas Islami dalam Perspektif AlQur'an. Edifional Journal, Vol. 1, No.1.

Kementerian Kesehatan Republik Indonesia. (2016). Situasi Kesehatan Reproduksi Remaja. https://www.kemkes.go.id/article/view/1 5090200001/situasi- kesehatanreproduksi-remaja.html.

Kemendikbud, U. d. (2016). Panduan Guru: Pencegahan dan Penanganan Kekerasan Seksual Pada Anak Usia Dini Di Indonesia. Jakarta: Unesco.

Nolte, L.D. (1998). Children Learn What They Live: Parenting to Inspire Value. New York: Workman Publishing Company.

Peraturan Pemerintah Pengganti UU No 1 tahun 2016 tentang Perubahan Kedua atas UU No 23 tahun 2002 tentang Perlindungan Anak.

Purnawan, I. (2004). Faktor-Faktor yang Mempengaruhi Pelecehan Seksual pada Anak Jalanan di Stasiun Kereta. Progam Jik Vol. 7 No. 1 Studi Ilmu Keperawatan. Yogyakarta: Universitas Gajah Mada. 
Rosyidah, F.N \& Fadhil, N. (2018) Media Sosial sebagai Ruang Baru dalam Tindak Pelecehan Seksual Remaja. SOSIOGLOBAL: Jurnal Pemikiran dan Penelitian Sosiologi, Vol. 2, No.2.

Setyati, E.S. (2006). Hubungan Pola Asuh Otoriter dengan Perilaku Remaja. Yogyakarta: Universitas Gajah Mada.

Suryati Romauli, S (2009). Kesehatan Reproduksi untuk Mahasiswa Bidan. Yogyakarta: Nuha Medika.

Triwijati, N. K. E. (2007). Pelecehan Seksual : Tinjauan Psikologis. Surabaya : Universitas Surabaya

Tim Redaksi KBBI Pusat Bahasa (2008). Kamus Besar Bahasa Indonesia. Jakarta: Gramedia.
Undang-undang Republik Indonesia No. 23 Tahun 2002 tentang Perlindungan Anak Undang-undang No. 4 tahun 1979 Tentang Kesejahteraan Anak.

Wahyuni, S. (2016) Perilaku Pelecehan Seksual dan Pencegahan secara Dini Terhadap Anak. RAUDHAH, Vol.IV, No.2, 2338-2163.

Winarno Budi. (2002). Isu-Isu Global Kontemporer. Yogyakarta: PT. Buku Seru. Widyastuti. (2009). Kesehatan Reproduksi. Yogyakarta: Fitramaya.

Witkowska, E. E. (2005). Perceptions of Sexual Harassment In Swedish High School, Public Health. 15 , 78-85 